Article title: A Strategy for Improved Student Success and Learning with E-Portfolios in Economics: A Case Study from the University of South Africa

Authors: Zurika Robinson[1]

Affiliations: Economics, University of South Africa[1]

Orcid ids: 0000-0001-6375-7535[1]

Contact e-mail: robinz@unisa.ac.za

License information: This work has been published open access under Creative Commons Attribution License http://creativecommons.org/licenses/by/4.0/, which permits unrestricted use, distribution, and reproduction in any medium, provided the original work is properly cited. Conditions, terms of use and publishing policy can be found at https://www.scienceopen.com/.

Preprint statement: This article is a preprint and has not been peer-reviewed, under consideration and submitted to UnisaRxiv for open peer review.

DOI: 10.25159/UnisaRxiv/000013.v1

Preprint first posted online: 15 April 2021

Keywords: open distance e-learning, e-portfolios, economics 


\title{
A Strategy for Improved Student Success and Learning with E-Portfolios in Economics: A Case Study from the University of South Africa
}

\author{
Zurika Robinson \\ https://orcid.org/0000-0001-6375-7535 \\ University of South Africa \\ robinz@unisa.ac.za
}

\section{Abstract}

Owing to the COVID-19 pandemic, more education will be conducted online worldwide. Problem-solving initiates alternative assessments such as eportfolios and continuous assessments. The Public Economics module for thirdyear students at the University of South Africa has gone fully online with eportfolios from 2021. This strategy has been implemented as a follow-up to the research findings of Robinson. The findings suggest that the final marks of Microeconomics have a significant impact on the results of the final-year students in Economics. Other factors such as assignment marks and module repeats played a role. The results reaffirm the importance and influence of Microeconomics as base knowledge for undergraduate and future postgraduate work. In addition, the findings indicate that the more the students tend to repeat or qualify for supplementary examinations, the higher the probability of them not progressing. The conclusion reaffirms the importance and influence of microeconomics as base knowledge for undergraduate and future post-graduate work. The importance of assignments emphasises the use of continuous assessment and thus e-portfolios in Economics. Future research entails further econometric and empirical work on the impact of the e-portfolios on third-year student success in Economics. E-portfolios are beneficial; if kept simple, they can provide students with continuous learning. However, e-portfolios need more lecturer feedback and self-directed learning for students to succeed.

Keywords: open distance e-learning, e-portfolios, economics

\section{Introduction}

The main aim of this research is to revisit and follow up on empirical research that has been conducted in the Department of Economics at the University of South Africa (Unisa). Low success rates at higher education institutions instigated renewed interest in the predictors of academic achievement (Keeve, Naude, and Esterhuyse 2012). This is also the case for the Economics module as discussed in this paper. Empirical research has been conducted in the Department of Economics at Unisa, with the earliest example 
from Pretorius, Prinsloo and Uys (2009) and more recent research from Robinson (2018).

Firstly, the study pictures the open distance e-learning (ODeL) environment within the theory of connectivism and self-directed learning. Secondly, it attempts to investigate the student success in the Public Economics third-year level module, with the success rate as the dependent variable. The study tests the impact of expertise such as first-year and second-year Macro- and Microeconomics as prerequisites for Public Economics students' success. The possibility of repeated candidates progressing to the next level intensifies. Lastly, it captures the pedagogic intervention as an e-portfolio as part of continuous assessment undertaken in Public Economics in an open, distance and online environment from 2021.

\section{Conceptual Background of Open Distance E-Learning}

In the wake of the COVID-19 pandemic, going more online worldwide will make ODeL crucial in years to come. It was not so long ago that distance education correspondence was primarily and extensively through the physical mail delivery system for both study materials and feedback. However, this has changed in recent years, which can be attributed to distance education becoming open and "most industrialised education" (Peters 2010). In economics, this change is attributed to the division of labour, mechanisation, capital-intensive techniques, specialisation, economies of scale, and mass production and distribution.

Distance education is increasingly advanced through technological improvements, leading to improvements in ODeL. On the African continent and in other developing countries, internet connection issues have historically been a challenge, resulting in problems with the delivery and submission of material online. However, increased mobile presence, together with advances in technology, improved the delivery and submission of material online. Open access resources and massive open online courses have further broadened educational horizons (open distance learning (ODL)). Technology continues to advance in all spheres, with its use in communication in all forms exceeding expectations. Technological applications reach beyond this, necessitating that quality, security, and other aspects keep pace, thereby providing a strong and secure foundation for users and developers. Distance education needs to be in sync with these processes to ensure that the sharing and collaboration of knowledge, innovation in processes, and the practices of transfer and communication will benefit both the learner and society in general.

ODeL employs concepts and methodologies similar to those practised by contact learning institutions, with the social interaction largely absent. Teachers, lecturers, and other instructors should provide learners with procedures and designs that represent the best practice to help them excel through perseverance, ambition, and aptitude. More research, feedback, analyses, and redesign might be required to build a system that 
moves this process forward, although many of the seeds are already sown. As people vary across the world, their ideas, methodologies and structures also vary. However, many will also be very comparable, if not the same, across the divide. The Open University in the UK refers to open as open to people, open to places, and open to ideas, to mention a few. Higher education has become more open: more than 250 universities have become part of the open educational resource movement (D'Oliveira and Lerman 2009). The internet in the twenty-first century has opened various possibilities but also has challenges of access, quality, and cost. The principles of technology such as division of labour, specialisation, and economies of scale again become paramount. Various South African residential universities have adopted the principle of open access, although to a limited extent. The degree of openness is therefore visible and includes the way in which the content is received and utilised by the learner. Unisa prides itself on bringing education to the underprivileged and can therefore be regarded as a truly open institution. In contrast to working adults, the young population of students who are not yet in full-time employment poses additional challenges and opportunities, where they enjoy participating in group discussions or online chats (Letseka and Pitsoe 2013).

\section{Connectivism and Self-Directed Learning}

The theory of connectivism is a recent addition, with online learning becoming a selfdirected activity. Heutagogy (knowing how and where to learn) explains selfdetermined learning, expanding on andragogy, in which the learner decides the path of learning (Hase and Kenyon 2000). In a heutagogical approach to teaching and learning, learners are highly autonomous and self-determined and emphasis is placed on the development of learner capacity and capability to produce learners who are wellprepared for the complexities of today's workplace. Learning occurs as a result of creating environments or networks (Siemens 2005). However, lecturers and instructors still need to place the needs of the students first, as many may not yet be prepared for self-directed learning. Greater empathy and instant feedback from the instructors will ensure students remain inspired and focused. Connectivism, especially at the graduate level, brings most things together, although the role of behaviourism, cognitivism and constructivism should not be ignored (Siemens 2005).

Conradie (2014) explored whether self-directed learning takes place through connectivism in personal learning environments. Although andragogy, behaviourism, cognitivism and constructivism all rely on the learner's know-how, connectivism goes a step further and involves an active learner engaging in learning through systems and networks and the know-where. Self-directed learning thus refers to an active learner designing his/her learning path through e-learning or Web 2.0 participation and collaboration between learner and lecturer or tutor. As part of the methodological analyses, 76 participants in an Information and Communication Technology class were included. Interviews were conducted with open- and closed-ended questions in terms of motivation, engagement, collaboration and self-actualisation. The main idea was to establish whether connectivism leads to more motivated learners, higher engagement by learners, facilitating more collaboration between learners and more encouraged learners. 
The main findings showed that learners were motivated and engaged supported by collaboration and self-actualisation. The learners did, however, find the self-direction challenging - especially in the beginning when more training became essential. Selfdirection can thus become a factor that predicts student success although not always measurable without questionnaires.

In the current context, it was fitting to explore, firstly, the factors that best explain the success rate of students. The closest example relating to the current context is student performance in Economics and the effect of expertise in related subjects (Wagemans, Valcke, and Dochy 1991). Concerning the influence of prior knowledge on the acquisition of subject-oriented knowledge, their regression analysis revealed that expertise accounted for 37 to 42 per cent of the variance in post-test scores. This relates to the focus in the current study where the influence of second-year modules as prerequisites was also tested. Du Plessis, Müller, and Prinsloo (2005) first investigated the profile of first-year Accounting students and the factors that influence the performance of these students in the ODL context. Another close comparison is that of the first-year Economics students by Pretorius, Prinsloo, and Uys (2009) in an ODL environment, where the researchers found that the successful passing of assignments had the greatest influence on student success, with language and age also playing a role. Some attention has been given to academic development and pedagogic intervention as tools to improve results.

Smith and Edwards $(2007,99)$ suggest that an academic development preparation course has a major influence on students' performance in first- and second-year Microeconomics. Matriculation results, Mathematics, English as the first language, Physical Science and gender were all important determinants of success. Smith (2009) further found that pedagogic interventions have a positive influence on the success of Economics students. The key variables that may explain the relative success of such intervention in the academic development course were economic, language and communication tutorials, essay writing, the module designed to develop students' quantitative and graphical skills, and smaller class sizes. Improved performance by the mainstream cohort may be ascribed, among other things, to a more intensive tutorial system. Keeve, Naude, and Esterhuyse (2012) found that for three-year curriculum students, academic factors such as Grade 12 performance and language proficiency provide a significant explanation. These factors do not apply to four-year curriculum students, where psychosocial factors may play a role. Smith and Ranchhod (2012) later concluded that educational interventions in the first year of Economics had a positive influence on academic performance. Their results further suggested that educational interventions introduced later, in the form of voluntary workshops, improved academic performance further.

Further international studies have been conducted on student success in Economics. Athey et al. (2007) investigated graduate economics education and student outcomes. They found that first-year grades in required core courses were a strong predictor of 
Economics graduate students' job placements. First-year Micro- and Macroeconomics grades were statistically significant predictors of student job placement. One explanation is that these courses directly help to prepare students to be successful researchers. Students could also gain self-confidence or create positive "first impressions" with faculty members. Foreign-trained and male students achieved higher first-year grades on average than their female counterparts. Further international research investigates the "historically disadvantaged or undeserved student" success and finds a significant impact of reading motivation, math and critical thinking skills on macroeconomics student success (Brown-Robertson, Ntembe, and Tawah 2015). This relates well with the Unisa environment also where these students might have fewer resources than their peers at residential universities. We have done extensive research in the Department of Economics to improve also our professional qualification mix over time (forthcoming research from Robinson in 2021). Mathematical and critical thinking skills as part of the curriculum became evident.

Unisa can be regarded as a truly open institution, taking pride in bringing education to the many underprivileged people in society, who cannot afford either the cost or the time to attend a contact institution. The vision and mission statements relate to its African character, with lifelong learning catered for through a high-quality open learning environment. Social justice is naturally encouraged, but also the development of underprivileged people. Unisa is fortunate to have a growing student population, although the associated cost implications and constraints require careful and forwardlooking management. In 2020, venue-based examinations have changed to an online platform, with authentication through invigilator applications. Unisa has also adopted a policy of continuous assessment, which makes formative assessment 100 per cent, with a variation of e-portfolios as a summative assessment. Unisa has transformed from the traditional and predominantly paper-based medium to the digital medium with reliance on the internet for its e-learning.

Many citizens of the developing world have not had the opportunity of reaching their full potential through the opportunities that tertiary education provides. Generations of talent have been lost and continue to be lost, either through infrastructure or through economic constraints. Although historic injustices are attributed to many constraints, ODeL institutions such as Unisa continue to deal with these challenges and opportunities, especially concerning South Africa and other countries on the African continent. Availability and access to funds will continue to pose a challenge, with ODeL being driven by both needs and necessity to fully adopt and exploit quality education through state-of-the-art technology. Different institutions in various continents will cater for the demands, needs and opportunities in their specific geographic locale, influencing not only the curriculum offered but also the learners seeking admission. 


\section{Research Methodology and Data: Public Economics at Unisa}

Public Economics at BCom final-year level in Economics is offered as a compulsory module. Microeconomics at the second-year level serves as a prerequisite for Public Economics (research from Robinson 2018). The data for the empirical analysis drew on the first- and second-semester registrations for 2016 and 2017. These samples consisted of approximately 500 to 1000 students.

The subject matter of Public Economics at third-year level is challenging to students. It is an applied microeconomics discipline and students sometimes struggle because their knowledge and comprehension of second-year Microeconomics may not suffice. The student needs to gradually progress to the next level through the successful understanding and mastering of earlier material. With a low pass rate, research and understanding of contributing factors, together with potential solutions for assistance and improvement have become critical.

\section{Profile of Students}

The group comprised mainly male students (see Table 1) with a mean age of approximately 31 , and who mostly did not study in their home language. The home language is included in the analysis as a reliable indicator of student success. Students who were unemployed or not economically active were regarded as full-time students. Those who were not classified were included as part-time students. Within the ODeL tuition and delivery framework, students only need to submit two assignments during the semester. For this study, the handing in and passing of the two assignments were taken as showing effort and commitment on the part of the student.

Table 1: Descriptive statistics in Public Economics for 2016 and 2017

\begin{tabular}{|l|l|l|l|l|l|}
\hline Variable & Sample & Mean & $\begin{array}{l}\text { Standard } \\
\text { Deviation }\end{array}$ & Minimum & Maximum \\
\hline FINALMRK & 1582 & 49.06 & 17.08 & 6 & 85 \\
\hline FINMRK_MICRO_1 & 1582 & 63.66 & 11.75 & 50 & 95 \\
\hline FINMRK_MICRO_2 & 1582 & 59.99 & 8.89 & 50 & 88 \\
\hline DUM_FULL & 1582 & 0.33 & 0.47 & 0 & 1 \\
\hline DUM_HL & 1582 & 0.39 & 0.49 & 0 & 1 \\
\hline DUM_MALE & 1582 & 0.49 & 0.50 & 0 & 1 \\
\hline AGE & 1582 & 30 & 7.39 & 20 & 57 \\
\hline ASS 1 & 1582 & 47.50 & 18.97 & 10 & 100 \\
\hline ASS 2 & 1582 & 47.74 & 22.55 & 10 & 100 \\
\hline
\end{tabular}

\section{Empirical Methodology and Model Specifics}

To assist the student, we needed to understand the determining factors in terms of student performance. The model was designed according to previous studies (Pretorius, 
Prinsloo, and Uys 2009), but additional variables have also been chosen to support the discussion behind the success rate of Public Economics students at the third-year level, namely:

OUTPUT Final_mark_Public_Ecn_3 = f (Age, N_Ass_1, Ass_1, Dum_fulltime, Dum_HL, Dum_male, Final_mark_Micro 1, Final_mark_Micro_2).

The dependent variable is effectively the final mark reached, while using a dummy variable to indicate pass or failure (see Table 2).

The coefficients, or explanatory variables (see Table 2), consist of the following: Age, assignment marks, dummy time variable ("Dum_fulltime", with a value of 1 for fulltime study, else 0), dummy language variable ("Dum_HL", with a value of 1 for study in the home language, else 0), dummy gender variable ("Dum_male", with a value of 1 if for male, else 0 if female), final mark reached in micro 1 , a final mark reached in micro 2 (see Table 3 ).

Table 2: Description of variables for Public Economics

\begin{tabular}{|l|l|}
\hline Dependent variables & \multicolumn{2}{|l|}{} \\
\hline Finalmark_Public_Ecn_3 & $\begin{array}{l}\text { Final mark scored by the student in Public } \\
\text { Economics 3 }\end{array}$ \\
\hline Dum_Final & Taking a value of 1 if passed and 0 if failed \\
\hline Explanatory variables & Age of the student \\
\hline Age & Mark of assignment 1 \\
\hline Assignment_1 & Mark of assignment 2 \\
\hline Assignment_2 & Final mark in Microeconomics 1 \\
\hline Finalmark_Micro_1 & Final mark in Microeconomics 2 \\
\hline Finalmark_Micro_2 & Number of times repeated Public Economics 3 \\
\hline Repeats & Number of times repeated Microeconomics 1 \\
\hline Repeat_Micro_1 & Number of times repeated Microeconomics 2 \\
\hline Repeat_Micro_2 & $\begin{array}{l}\text { Taking a value of } 1 \text { if studying in home language } \\
\text { and 0 if not }\end{array}$ \\
\hline Dum_HL & $\begin{array}{l}\text { Taking a value of 1 for male students and 0 for } \\
\text { female students }\end{array}$ \\
\hline Dum_Male & $\begin{array}{l}\text { Taking a value of 1 for full-time students and 0 for } \\
\text { part-time }\end{array}$ \\
\hline Dum_full & \multicolumn{2}{|l}{}
\end{tabular}


Table 3: Ordinary least squares with final mark Public Economics as dependent

\begin{tabular}{|l|l|l|l|l|}
\hline Variable & $\begin{array}{l}\text { Coefficient } \\
(\mathbf{2 0 1 6 )}\end{array}$ & Prob. & $\begin{array}{l}\text { Coefficient } \\
\mathbf{( 2 0 1 7 )}\end{array}$ & Prob. \\
\hline C & -4.830956 & 0.6342 & -1.170508 & 0.9321 \\
\hline FINMRK_MICRO_1 & 0.261136 & 0.0296 & 0.261455 & 0.0694 \\
\hline FINMRK_MICRO_2 & 0.527615 & 0.0007 & 0.287709 & 0.1225 \\
\hline DUM_FULL & -2.278547 & 0.4174 & 1.641492 & 0.6293 \\
\hline DUM_HL & -2.463564 & 0.3083 & -5.570142 & 0.0709 \\
\hline DUM_MALE & -2.131487 & 0.3603 & 2.562213 & 0.3958 \\
\hline AGE & 0.131861 & 0.4507 & 0.084011 & 0.7273 \\
\hline ASS 1 & 0.128275 & 0.0399 & 0.123274 & 0.0689 \\
\hline ASS 2 & -0.033888 & 0.5252 & 0.048321 & 0.5297 \\
\hline R-squared & 0.181943 & & 0.117993 & \\
\hline Observations & 582 & & 392 & \\
\hline
\end{tabular}

The low predictive power or R-squares of the regressions can be explained by the fact that this study focused on student-specific factors only, and thus ignored the characteristics of the specific institution, the impact of curriculum choices, and the impact of the characteristics of the staff involved in teaching, including e-learning solutions, that may almost certainly also have an impact on student success (see Pretorius, Prinsloo, and Uys 2009).

The results suggest that the final marks of first- and second-year Microeconomics have a significant impact on the final mark of Public Economics (Table 3). This was to be expected as Public Economics is microeconomic based. The first-year level result coincides with the findings of Athey et al. (2007), in the sense that it is the core course or module for an economics graduate student. The better the student performs in the assignments, especially assignment 1 which is compulsory for examination entrance, the better the final mark of the student. Although home language can be considered a contributor, it is not consistent year on year because third-year students are senior and more mature in their studies. Indeed, many of the students can be regarded as studying part-time, and they may be active in an environment in which English is the main language of communication. Whereas age and the status of the student, full-time or parttime previously were factors, the results tend to show insignificant outcomes. The conclusion needs to be made that each group of students are unique and that results need to be interpreted separately for different periods.

\section{Binary Logit Results}

OUTPUT Dum_final $=\mathrm{f}($ Repeats, Repeat_Micro_1, Repeat_Micro_2, Age, N_Ass_1, Ass_1, Dum_fulltime, Dum_HL, Dum_male). 
For Public Economics, the dependent variable is the dummy final mark, which takes a value of 1 when Public Economics was passed and 0 when it was failed. Table 4 shows the binary logit results. The results of the binary logit models are interpreted differently from the ordinary least squares (OLS) results. It was found that the more the students repeated Public Economics in previous years of study, the more their probability to pass Public Economics decreased. The more they repeated second-year Microeconomics, the more their probability of passing Public Economics decreased. The assignments are important and the better the students perform in the assignments, the better their chances are to pass Public Economics. Although inconsistent year on year, home language could still be considered a factor, which tends to affect the students' chances of passing Public Economics.

Table 4: Binary logit results with dummy final of Public Economics as dependent variable

\begin{tabular}{|l|l|l|l|l|}
\hline Variable & $\begin{array}{l}\text { Coefficient } \\
(\mathbf{2 0 1 6 )}\end{array}$ & Prob. & $\begin{array}{l}\text { Coefficient } \\
(\mathbf{2 0 1 7})\end{array}$ & Prob. \\
\hline C & 0.698377 & 0.0667 & -0.312897 & 0.4915 \\
\hline REPEATS_PUBLIC_ECN_3 & -0.704585 & 0.0000 & -0.385772 & 0.0003 \\
\hline REPTS_MICRO_1 & 0.272720 & 0.0326 & -0.074959 & 0.6011 \\
\hline REPTS_MICRO_2 & -0.050736 & 0.6112 & 0.049351 & 0.6755 \\
\hline DUM_HL & 0.405600 & 0.0690 & -0.076426 & 0.7749 \\
\hline DUM_MALE & -0.287058 & 0.1581 & 0.037640 & 0.8710 \\
\hline DUM_FULLTIME & -0.469520 & 0.0358 & -0.102650 & 0.6708 \\
\hline ASS1_ & 0.011021 & 0.0528 & 0.012691 & 0.0229 \\
\hline ASS2_ & 0.011145 & 0.0229 & 0.010231 & 0.0850 \\
\hline MacFadden R-Squared & 0.151876 & & 0.062255 & \\
\hline Observations & 582 & & 392 & \\
\hline
\end{tabular}

To verify the regression results, we explained the repeats in terms of a binary logit method. We found that the more the students repeated the Public Economics, the more the probability to pass the module decreased. The repeats include candidates for supplementary examinations. The causal effects are not always clear-cut but we do know that some candidates become constant "repeaters" and that these candidates do not normally register again for the modules and then do not qualify for student support. However, academic progression rules should place a cap on the tendency of constant repetition in the longer run. 


\section{E-Portfolios as a Strategy for Improved Student Success and Learning}

An electronic portfolio (e-portfolio) can be defined as

a collection of electronic evidence assembled and managed by a user, usually on the Web. Such electronic evidence may include input text, electronic files, images, multimedia, blog entries, and hyperlinks. E-portfolios are both demonstrations of the user's abilities and platforms for self-expression. If they are online, users can maintain them dynamically over time. One can regard an e-portfolio as a type of learning record that provides actual evidence of achievement. (Wikipedia, s.v. "Electronic portfolio")

E-portfolios represent alternative assessments to formative or continuous assessments. Some challenges exist and Beckers et al. (2019) found that students needed extra support and feedback from their lecturers regarding the use of e-portfolios. The authors also found that the imbalance between autonomy and support hampered self-directed learning and motivation.

Developing an e-portfolio can offer numerous benefits as an assessment tool, allowing assessment to be a continuous process, developmental, and performance-based (Lambe, McNair, and Smith 2013). A Facebook-based e-portfolio had a positive impact on students' writing practices, making it a viable tool for e-portfolio assessment (Barrot 2016). The students' perceptions in the e-portfolio group reflected that they benefited and enjoyed keeping a portfolio (Baturay and Daloğlu 2010). The portfolio project helped students better understand learning goals, think about what they have learned in college, and reflect on the knowledge and skills they have developed. In addition to the surveys, rubrics used to assess student portfolios were collected and reviewed to evaluate the efficacy of e-portfolios as an assessment measure with positive findings revealed (Buzzetto-More 2010). Digital portfolios with numerous aids are beneficial to teacher reflection and professional development (Sung et al. 2009).

From the e-portfolio data analysis, it appears that self-directed learning occurs through self-appraisal by student teachers reflecting on their values, learning styles, and learning strategies to enhance self-efficacy. The bricolage of evidence produced by student teachers indicated that e-portfolios as an empowering tool enhanced students' selfdirected development into competent teachers who are well-grounded in the knowledge, skills, values, principles, methods, and procedures relevant to the teaching of Economics in the Further Education and Training phase. Moreover, higher education institutions must implement a mentorship to support students in building good relationships as part of e-portfolio development (Van Wyk 2017). The Department of Economics at Unisa chooses to base its programmatic assessment on the Hansen proficiencies or something similar and should gain much from the insights. The real winners of a serious approach and implementation of programmatic assessment are the students and those who later benefit from their analytical talents (Myers, Nelson, and Stratton 2009). Another critical issue that needs to be dealt with is invigilation and the numerous views against online 
proctoring, making ethical issues more visible (Selwyn et al. 2021). The use of software tools such as Turnitin should also assist in authenticating assignment results.

We have switched to a fully online module with an e-portfolio as a summative assessment. Because this is an online module, four assignments are given in the study material as they become due during the module and should entail more effort as part of continuous assessment than only two assignments previously. The students can see them when they go online four weeks before the due date. The e-portfolio can be done on Google sites, Mahara and WordPress. It consists of the biography and photo of the student, a reflective journal that consists of a summary of all the research done on activities throughout the semester, artefacts, and all the assignments. As the module progresses, we will expand this to include PowerPoint presentations. In this way, the work is also authenticated as the student's work because online authentication is complex. The students need to research each activity of each lesson fortnightly. The activity should be 100 words and is included in the e-portfolio.

Assignment 1 is an online assessment with multiple-choice questions and is a challenging question bank with random questions selected for the students. Assignment 2 is a group discussion that is done online on Kialo at https://www.kialoedu.com/my. A total of 15 groups of 30 students in each group are invited via email to participate in the discussion. The students need to post their discussion threads and review them. The appointed leader will then post the summary in the Dropbox function on myUnisa. Marks will then be awarded for the different groups. Assignment 3 consists of one essay type of question that follows up on the group discussion claim, for example: "Government could have gained more revenue through higher excise duties, rather than banning the trade of tobacco products during the Covid-19 pandemic." The student's argument should consider whether health should be a private or public good.

The student should also explain who bears the burden of an ad valorem excise duty on tobacco products levied on sellers if there is perfect competition and relatively inelastic demand. If the demand is relatively inelastic, could the Ramsey rule be applicable? The student should use diagrams as part of the answer and should consult lessons 2, 8, and 9. For research purposes, the student should use Google Scholar to find relevant accredited academic articles. The student should also use the Palgrave Dictionary of Economics for definitions available online in the library. The student needs to use the Harvard referencing method in citations and reference lists (see the library guides). Grammarly online can be used to check grammar. We allow a maximum amount of 2000 words. The student can submit the written assignment as a pdf file on myUnisa after ensuring that the language is correct and the assignment is legible. The marked assignment will be returned to the student, and an extensive rubric serves as a guide in doing the assignment.

We expect that the learning will become much more self-directed, and lecturer feedback will have to be given frequently. We have developed this as part of an improvement 
plan for the module as a better option than online examinations and venue-based examinations. To evaluate whether the e-portfolio meets the requirements for the curriculum set, Hansen's proficiencies, which are similar to Bloom's taxonomy, are used. Students build up an essay; they first have to analyse data from newspapers and journals and discuss claims set in Kialo.

Although we have only started using the e-portfolios in 2021, we hope to get feedback from Public Economics students through a survey conducted in future and report these results as soon as possible. At this stage, an e-portfolio seems to be the best alternative to venue-based examinations and online examinations. Evidence already exists, and most of the views of teachers and students in Economics can be summarised (Van Wyk 2017). The e-portfolios help teachers to become confident in their teaching and selfdirected in their learning. Reflective journals help to capture feelings and thoughts and to implement pedagogy in teacher practices.

\section{Conclusion}

This paper explained the use of e-portfolios in the third-year Public Economics module as a strategy to improve student success and learning. First, ODeL was described and explained within connectivism and self-directed learning. The literature review discovered that extra student support and immediate feedback from the lecturer were needed. The benefits of an e-portfolio include an effective assessment that could be continuous, self-directed learning, and motivation. From the description of using the eportfolios in the Public Economics module, it became clear that more assignments with continuous feedback throughout the semester should deal with concerns from previous empirical findings in the research of Robinson (2018). In future, a survey will be conducted in the Public Economics module to get students' views about the new eportfolio format and assessment. Further econometric and empirical work will investigate the impact of the e-portfolios on student success in third-year Economics.

\section{References}

Athey, S., L. E. Katz, A.B. Krueger, S. Levitt, and J. Poterba. 2007. "What does Performance in Graduate School Predict? Graduate Economics Education and Student Outcomes." AEA Papers and Proceedings 97 (2): 512-18. https://doi.org/10.1257/aer.97.2.512.

Barrot, Jessie S. 2016. "Using Facebook-Based E-Portfolio in ESL Writing Classrooms: Impact and Challenges." Language, Culture and Curriculum 29 (3): 286-301. https://doi.org/10.1080/07908318.2016.1143481.

Baturay, Meltem Huri, and Ayşegül Daloğlu. 2010. "E-Portfolio Assessment in an Online English Language Course.” Computer Assisted Language Learning 23 (5): 413-28. https://doi.org/10.1080/09588221.2010.520671. 
Beckers, Jorrick, Diana H. J. M. Dolmans, Michelle M. H. Knapen, and Jeroen J. G. van Merriënboer. 2019. "Walking the Tightrope with an E-Portfolio: Imbalance between Support and Autonomy Hampers Self-Directed Learning." Journal of Vocational Education and Training 71 (2): 260-88. https://doi.org/10.1080/13636820.2018.1481448.

Brown-Robertson, La Tanya N., Augustin Ntembe, and Regina Tawah. 2015. "Evaluating the 'Underserved Student' Success in Economics Principles Courses." Journal of Economics and Economic Education Research 16 (3): 13-24.

Buzzetto-More, Nicole A. 2010. "Assessing the Efficacy and Effectiveness of an E-Portfolio Used for Summative Assessment." Interdisciplinary Journal of E-Skills and Lifelong Learning 6: 061-085. https://doi.org/10.28945/1164.

Conradie, P. W. 2014. "Supporting Self-Directed Learning by Connectivism and Personal Learning Environments." International Journal of Information and Education Technology 4 (3): 254-59. http://doi.org/10.7763/IJIET.2014.V4.408.

D’Oliveira, C., and S. Lerman. 2009. "OCW: Working through Financial Challenges." Accessed 4 May 2018. http://web.mit.edu/fnl/volume/221/d\%27oliveira_lerman.html.

Du Plessis, A., H. Müller, and P. Prinsloo. 2005. "Determining the Profile of a Successful First-Year Accounting Student.” SAJHE 19 (4): 684-98. https://doi.org/10.4314/sajhe.v19i4.25656.

Hase, S., and C. Kenyon. 2001. "From Andragogy to Heutagogy." http://www.psy.gla.ac.uk/ steve/pr/Heutagogy.html.

Keeve, A., L. Naude, and K. Esterhuyse. (2012). "Some Predictors of Academic Performance of First-Year Students in Three- and Four-Year Curricula." Acta Academica 44 (1): 12158 .

Lambe, Jackie, Victor McNair, and Ron Smith. 2013. "Special Educational Needs, E-Learning and the Reflective E-Portfolio: Implications for Developing and Assessing Competence in Pre-Service Education.” Journal of Education for Teaching 39 (2): 181-96. https://doi.org/10.1080/02607476.2013.765191.

Letseka, M., and V. Pitsoe. 2013. "The Challenges and Prospects of Access to Higher Education at UNISA." Studies in Higher Education 39 (10):1942-54. https://doi.org/10.1080/03075079.2013.823933.

Myers, Steven C., Michael A. Nelson, and Richard W. Stratton. 2009. “Assessing an Economics Programme: Hansen Proficiencies, EPortfolio, and Undergraduate Research." International Review of Economics Education 8 (1): 87-105. https://doi.org/10.1016/S1477-3880(15)30077-3.

Peters, O. 2010. Distance Education in Transition, Developments and Issues. 5th ed. Oldenburg: BIS verlag der Carl von Ossietzky Universität Oldenburg. 
Pretorius, A. M., P. Prinsloo, and M. D. Uys. 2009. "Student Performance in Introductory Microeconomics at an African Open Distance Learning Institution." Africa Education Review 6 (1): 140-58. https://doi.org/10.1080/18146620902857574.

Robinson, Z. 2018. "Predicting Student Success in Public Economics.” International Journal of Economics and Finance Studies 10 (2): 55-72. http://www.sobiad.org/eJOURNALS/journal_IJEF/archieves/IJEF_2018_2/z-robinson.pdf.

Selwyn, Neil, Chris O’Neill, Gavin Smith, Mark Andrejevic, and Xin Gu. 2021. “A Necessary Evil? The Rise of Online Exam Proctoring in Australian Universities.” Media International Australia https://doi.org/10.1177/1329878X211005862.

Siemens, G. 2005. “Connectivism: A Learning Theory for the Digital Age.” International Journal of Instructional Technology and Distance Learning 2 (1).

Smith, L. C. 2009. "An Analysis of the Impact of Pedagogic Interventions in First-Year Academic Development and Mainstream Courses in Microeconomics." South African Journal of Economics 77 (1): 162-78. https://doi.org/10.1111/j.1813-6982.2009.01195.x.

Smith, L., and L. Edwards. 2007. "A Multivariate Evaluation of Mainstream and Academic Development Courses in First-Year Microeconomics.” South African Journal of Economics 75 (1): 990150117. https://doi.org/10.1111/j.1813-6982.2007.00102.x.

Smith, L. C., and V. Ranchhod. 2012. "Measuring the Impact of Educational Interventions on the Academic Performance Second-Year Microeconomics." South African Journal of Economics 80 (3): 431-48.

Sung, Y. T., K. E. Chang, W. C. Yu, and T. H. Chang. 2009. "Supporting Teachers' Reflection and Learning through Structured Digital Teaching Portfolios: Original Article." Journal of Computer Assisted Learning 25 (4): 375-85. https://doi.org/10.1111/j.13652729.2009.00312.x.

Van Wyk, Micheal M. 2017. “Exploring Student Teachers' Views on Eportfolios as an Empowering Tool to Enhance Self-Directed Learning in an Online Teacher Education Course." Australian Journal of Teacher Education 42 (6): 1-21. https://doi.org/10.14221/ajte.2017v42n6.1.

Wagemans, L. J., M. Valcke, and F. Dochy. 1991. "Learning Economics at a Distance: Quality and Impact of Expertise. A Study with Open University Students." Distance Education 12 (2). https://doi.org/10.1080/0158791910120207.

Wikipedia, s.v. "Electronic portfolio," last edited 3 July 2021, 22:57, https://en.wikipedia.org/wiki/Electronic_portfolio. 